\title{
ENRICO FERRI
}

A Faculdade de Direito tambem recebeu a visita de Enrico Ferri, o celebre prufessor e sociologo italiano, que, com Cesare Lombroso, foi o fundador da nova escola positiva do Direito Penal.

A's I I horas da manhã do dia I 4 de Novembro, foi o egregio professor recebido pela mocidade academica com a mais enthusiastica manifestação de jubilo.

Ao penetrar no edificio da Faculdade, os estudantes, no meio dos mais estrepitosos applausos, atiraram flores sobre o eminente professor, que, á porta principal do edificio, foi recebido pelo Director e lentes da Faculdade, todos revestidos de béca.

Acompanhado pelo corpo docente e pelos alumnos, subio ao salão da Directoria, onde visitou a galeria dos Directores da Faculdade, e donde, após pequeno descanço, partiu a visitar a Bibliotheca e os outros compartimentos da Faculdade.

Introduzido no salão nobre, que se achava bellamente enfeitado, o Dr. Dino Bueno, director da Fa. culdade convidou o a tomar assento á sua direita na mesa da Presidencia, e dando á esquerda ao presidente do Centro academico, sentados os lentes nas suas cadeiras, no doutoral, fallou dando as boas vin- 
das a tão notavel scientista, como egregio professor, com cuja visita muito se honrava a Faculdade de Direito, e, em seguida, abrindo uma sessão solemne para n'ella especialmente recebel-o, deu a palavra ao lente Dr. Candido Motta para, em nome da Congregação, saudar a tão douto visitante.

O Dr Candido Motta pronunciou o seguinte discurso, que foi enthusiasticamente applaudido pelo audictorio :

Illustre e honrado professor Henrique Ferri; Senhor Doutor Director da Faculdade, caros mestres e collegas, minhas senhoras e meus senhores.

Quando em 1888, em Lucca, desappareceu no seu eterno occaso o astro poderoso, que durante mais de 40 annos illuminára a Universidade de Piza, a Italia gloriosa, recolhendo-se numa pungente consternação, cobriu-se toda de luto, e a sciencia penal julgou-se orphan.

Francisco Carrara, engenho rutilante, talento de elejção, natureza privilegiada de pensador e de philosopho, espirito communicativo e são, altas qualidades que delle faziam o mais preclaro dos mestres, resumia em si uma época inteira para sempre indestructivel nos fastos do pensamento humano.

Mais feliz que Archimedes, o jcvem marquez de Beccaria conseguira levantar com a sua minuscula alavanca o mundo espiritual numa homerica reacção contra as praticas e as doutrinas criminaes do seu tempo.

Quebrado o mysterio, dissolvida a prestigiosa auctoridade das idéas em voga, o espirito humano, como que rompendo um enclausuramento secular, rasgou largas estradas e desccrtinou novos e interminos horisontes. $\mathrm{O}$ mundo inteiro agitou-se. Como 
a pequena semente lançada em terra fecunda germina e se desenvolve, torna-se a arvore frondosa que a todos abriga com a slia sombra acariciante e salutar, a obra de Beccaria, germinou e desenvolveu-se. De cada palavra de seu maravilhoso livrinho surgiu uma idéa nova, de cada phrase em que mal se definia um pensamento indeciso brotavam, brilhantes e ousadas generalisações.

A França moveu se, e não contente com a inspiração de Jeremias Bentham, o principal collaborador do codigo de i 8 Io, falou tambem pelos orgams de Guisot e Victor Cousin, cujas idéas philosophicas acceitas e desenvolvidas por Pellegrino Rossi no seu monumental "Tratado do direito penal», culminaram nas reformas legislativas de i 832 .

A Hespanha, sempre ardente e impetuosa, quâo retardataria, pois ainda em I848, no dizer de $\mathrm{Pa}$ checo, continha em sua legislação todos os absurdos, todas as crueldades dos seis seculos anteriores, fez-se ouvir pelo orgam dulciloquo do inconstante Donoso Cortés.

A Allemanha com Feurbach, o glorioso autor do codigo penal da Baviera, a Austria com Sounenfeh e a Inglaterra com sir Robert Peel, não se deixaram ficar atraz no movimento progressivo das idéias.

Mas assim como nem todos os rebentos de uma planta têm a vitalidade necessaria para se desenvolver só vingaram á acção do tempo, do choque incruento das idéas, os dois grandes ramos que deram á sciencia penal a sua conformação actual.

Carmignani pontificava em Piza, mas roubado á patria e á sciencia cedia o lugar áquelle que "na sua obra multiforme, mas poderosamente symetrica e monumental, resumiu, numa synthese maravilhosa, 
a orientação critica forense com a philosophica e, por isso, foi acclamado soberano tanto na cathedra como no fôro"

A sua obra absorveu todos os espiritos e tal foi o encanto das suas palavras, a fascinação das suas idéas que, sem exaggero, podemos affirmar que Francisco Carrara, como um caudaloso rio, attrahiu e confundiu com as suas aguas as dos regatos visinhos, e, dominador, absoluto rompendo as distancias, vencendo as altitudes, derramou sósinho pelo universo inteiro as aguas lustraes da sua immensa sabedoria. $E$, assim quasi cego, coberto de louros, e das bençams dos seus contemporaneos, poude, afinal, repousar á sombra dos plangentes cyprestes da sua bella terra natal, levando comsigo a certeza daquillo que resumia a sua mais elevada aspiração - "a de ter inspirado aquelle doce palpitar, com a qual as almas sensiveis respondem a quem sustenta os interesses da humanidade».

Não é este o momento opportuno para resumir as suas idéias que todos conhecemos. Assignalo, apenas, que o seu imperio foi quasi absoluto no ultimo quartel do seculo passado, e que, por isso mesmo, o seu desapparecimento, sem que ninguem talvez então o presentisse, excedia á significação commum do desapparecimento de um mortal illustre, para representar, mais que tudo, o encerramento do cyclo glorioso de uma escola.

$\mathrm{O}$ vacuo que deixou em Piza não éra, por isso mesmo facil de ser preenchido.

Pedir continuadores para a sua obra era o mesmo que pedir á arvore secular, cujas raizes resequidas não sugam mais da terra a seiva vital para o seu organisamo valetudinario os fructos olentes d'outróra, é exigir da mulher que depois da menopausa não cesse de reproduzir a especie querida e preciosa 
Não, o terreno esterilisara-se, consumava-se mais um estadio fatal da evolução, e assim se enganavam os que confundiam um dos periodos desta, com o estaclo defenitivo ou terminal da sciencia.

E' que esta não pára. O espirito humano agita-se perennemente como as ondas do mar. e ao mesmo tempo que abysma para sempre nas profundezas do esquecimento as idéias refractarias á crystallisaçâo e não purificadas no seu eterno agitar, só conservava aquelles residuos, que passados por todos os seus cadinhos, são recolhidos pela sciencia e tornam-se impereciveis; como imperecivel é a verdade!

Mas ao pôr de um sol succede o nascer de outro e a Italia, que pisa o mar com a sua enorme bota, para significar que, eterno viajante, está sempre prompta a partir e levar, onde quer que a chamem, o contingente do seu braço fecundo e o palpitar constante do seu nobre coração, tem a cabeça repousada nos Alpes, majestosa como o sol em suas convulsões de tempos a tempos desarticula nebulosas que ornam o firmamento do saber humano em todas as suas manifestações, e que se chamam Vico e Pico, Giordano Bruno e Galileu, Christovam Colombo, Alexandre Volta e Marconi, Romagnosi e Carrara, Rafael de Sanzio e Miguel Angelo, Garibaldi, Mazzini, Cavour e Leão XIII, os Semola, Serafini, Paschoal Fiore, Vidale, Pietro Ellero, Ardigó, os Lombroso, os Garofalo, os Henrique Ferri!

Henrique Ferri! Criança genial, que aos 23 annos éra chamado a substituir o grande Pedro Ellero na Universidade de Bolonha e logo depois designado como o mais digno e o mais capaz de reger a cadeira que Carrara tanto illustrára!

Poucos annos antes da morte do grande luquez no recolhimento imperturbavel e sereno do sabio,- 
quer surprehender e desvendar os mysterios da sciencia, depois de ter visitado as prisões e os manico. mios, feito o campo de seus estudos, Cesar Lombroso dava á publicidade a sua obra capital - $O$ homem delinquente» - determinava uma nova orientação ao estudo do direito penal.

Iniciando uma éra brilhante para a sciencia, tornando-se o centro de um vasto movimento scientifico no campo de todas as uisciplinas biologicas e juridicas, reencetou investigações sobre o homem criminoso e convenceu-se de que este, por atavismo, degeneração ou paralysação do desenvolvimento, reproduz os caracteres psychicos e anatomicos do homem barbaro e selvagem.

Mas Lombroso era antes um investigador, um analysta meticuloso e pertinaz; as suas obras eram mananciaes preciosissimos de factos, pacientemente recolhidos e observados. Basta vêr a que minucias desceu quando foi buscar nos animaes e até nas plantas os equivalentes do crime e da pena!

Os seus estudos divulgados agitaram todos os espiritos e produziram a par do acolhimento sympathico dos homens de boa vontade e imparciaes, a furia tremenda das contestações, que nem sempre primaram pela delicadeza, ou pela originalidade.

Conta um dos seus criticos que certo dia enviaram ao preclaro professor a photographia de um artista de genio, e que elle, julgando tratar de um criminoso, descobriu-lhe certos signaes e estigmas que o faziam entrar no seu typo de criminoso nato.

Só com isso julgaram desmoralisada a obra que sabio levára annos e annos de paciente estudo a organisar, sem se aperceberem que essa éra uma manifestação grosseira da propria ignorancia, pois que 
o homem de genio apresentava tambem muitas vezes estigmas semelhantes aos do criminoso, extremos que são da mesma escala degenerativa.

Zimmerman, pretendeu tambem que Lavater tomasse um bandido por um homem dotado de todas as virtudes.

A falta de materia philosophica éra mui sensivel nas primeiras edições da obra de Lombroso. Eis, porém, que quasi parallelamente Henrique Ferri assombrava o mundo universitario com a sua these inaugural - "La theoria dell'imputabilitá e la negazione del libero arbitrio", surto ousado de um cerebro genial, e que, rompendo com as velhas theorias tradicionaes, deu ás investigações de Lombroso o complemento necessario para constituir o corpo de doutrina, perfeito e systematico de que a sua "Sociologia Criminal» é a maravilhosa e imperecivel synthese!

Ah! A navegação do livre arbitrio, nefando crime, que o grande espiritualista Terenzio Mauriani não podia admittir na sua consciencia de homem, de crente, de cidadão, e de philosopho num estudante que além de tudo tinha a ousadia de pretender uma cathedra na Universidade!

A despeito de ter conquistado com aquelle trabalho o premio de viagem ao extrangeiro para aperfeiçoar-se, prepararam-se os arsenaes, soaram os clarins de combate e a polemica irrompeu descortez e aggressiva.

Desde então, estabeleceu-se e firmou-se o consorcio dos ideaes do mestre e do discipulo, e a inveja e o despeito procuraram amesquinhar o seu trabalho, inverter as suas palavras, deturpar os seus pensamentos, confundindo-os numa mesma atmosphera de odios. A luta foi porfiada, mas desleal. Aos 
factos respondiam com syllogismos. Todo o mundo se julgou com direito de os criticar por meio de conceitos abstractos e formulas unilateraes.

Na imprensa, na iribuna, nos congressos scierficos, Lombroso e Ferri tiveram de ouvir e rebater a censura irreverente do mais graduado scientista ao mais boçal dos sapateiros.

O phenomeno era natural porque é lei de psychologia humana, toda a idéa nova levanta sempre contra si desconfiança e opposição. Qual a doutrina scientifica, qual o systhema politico, qual a religião que não tem oppositores?

A sciencia universal é muito grande para um só cerebro. Se, pelo entrelaçamento natural dos ramos do saber, temos obrigação de conhecer um pouco de tudo para bem conhecer a especialidade a que as tendencias do nosso espirito, o dever profissional e a lei natural da divisão do trabalho nos impellem, jámais devemos ter a ousada pretenção de tornarmonos os censores dos que cultivam ramo diverso do nosso.

Cada um em seu mistér.

E' por isso que Dante já dizia:

Sempre natura, se fortuna trova

Discorde a té, come ogni altra semente

Fuor di sua region, fa mala prova

E se'l mondo lagiú ponesse mente

Al fondamento che natura pone

Seguendo lui, avria buona la gente

Ma voi torcete alla religione

Tal che fu nato a cingersi la spata,

E fate re di tal ch'é da sermono

Onde la traccia vostra é fuor di strada.

(Paradiso C. $8^{\circ}$ ) 
Em sciencia experimental então é cúrioso que quem não tenha observações proprias pretende oppôr contradita ás dos que encanecem no labor quotidiano em busca da verdade.

Proceder assim, é comer por mão alheia, sem que ao menos tenha certeza da origem e da bôa qualidade dos acepipes.

Mas o resultado dessa verdadeira campanha de descredito não foi outro que o de tornar maiores aos olhos de todos os grandes pensadores italianos, que constituiram em todo mundo um proselytismo cada vez mais avassallador, e dia a dia se inculcam no conceito universal como os verdadeiros pioneiros desta nova crusada, que tem por fim dar á sciencia penal o seú verdadeiro papel e ás leis sociaes o seu verda. deiro caracter.

Póde-se dizer que o valor de um homem está na razão directa do valor e do numero dos seus adversarios.

Niguem combate a quem não tem um valor real ou uma capacidade offensiva e criadora, e essa capacidade criadora é o privilegio dos genios.

E' um facto curioso o que nos revela a historia dos grandes homens contadas pelos seus maiores inimigos.

Ninguem deixou tantos admiradores e ao mesmo tempo tão crueis adversarios como Napoleão I, esse flagello necessario, cuja acção do mesmo tempo que inspira horror, empolga a admiração universal.

Se quereis, porém, ter a impressão real da sua grandeza e do seu genio, nâo a busqueis na vasta bibliographia que constitue a epopéa napoleonica, porque mais alto que os Lascases e os Desiré Lacroix, mais alto que as paginas immoredouras da His- 
toria do Consulado e do Imperio, mais alto mesmo que Wagram, Iena e Austerlitz, falarn as tremendas objurgatorias do marquez de Chateaubriand, o mais implacavel dos seus inimigos, as paginas frias e crueis com que Hyppolito Taine procurou quebrar a aureola de heroismo que ainda hoje envolve o seu nome.

Assim direi, nunca a minha admiração por Henrique Ferri se tornou tão intensa, como quando os seus adversarios, revestindo-se de velhas armaduras, desorientados, investiram com impetuosidade tal que, offuscados pelo brilho da verdade, deram ás tontas as suas pancadas, sem perceberem que á theoria da escola positiva de direito penal, os seus golpes jámais attingiriam e que em breve, fatigados pelos insuccessos, não teriam outro recurso senão se curvarem reverentes ante a victoria esmagadora dos seus principaes arautos! Nunca me pareceu este tão grande como quando o espirito de um sectarismo revoltante, sob o pretexto de que a inamovibilidade dos professores não podia proteger a Ferri, diante das leis de incompatibilidade parlamentar, o privou da cathedra, a qual acaba de ser de novo chamado ao mesmo tempo que a França e a Belgica o acolhiam com enthusiasmo e, reclamavam os seus ensinamentos na «Ecole des Hautes études de Paris»e na "Université Nouvelle de Bruxellas»!

Pois bem, senhores, este velho mosteiro hoje inteiramente consagrado ao culto do direito e da justiça; esta vasta officina donde têm saido quasi todos aquelles de quem o Brazil mais se orgulha; este templo da liberdade, que jámais deu guarida á camorra universitaria ou camorra politica, onde todas as opiniões e todos os ideaes são recebidos e respeitados com o mais vivo e sincero acatamento, recebe a visita do insigne professor que o mundo dos sabios acclama entre os seus. 
Mestres e alumnos, confundidos no mesmo sentimento de cordialidade, embora nem todos compartilhem as suas doutrinas philosophicas e politicas, vêm hoje apresentar-lhe as suas mais cordiaes saudações. E eu, que para aqui entrei, o primeiro na America do Sul, disputando a cathedra que occupo, com os ideaes da nova escola penal, agradecendo ao meu bom amigo e mestre Doutor Director, a insigne honra de me ter designado para interpretar os sentimentos da congregaçâo, peço licença para declarar que, se não posso, infelizmente, dizer com o poeta florentino

"Tu se' solo colui, da cui io tolsi

Lo bello stilo che mi ha fatto onore,

posso, com justo orgulho e desvanecimento affirmar quaesquer que sejam os dissidios doutrinarios parciaes entre nós:

\footnotetext{
"Vagliami il lungo studio e il grande amore

Che mi ha fatto cercar il tuo volume

Tu se' il mio maestro, i! mio autore!"
}

Terminados os applausos merecidos pelo discurso do lente Dr. Candido Motta, fallaram os alumnos Antonio Covello, Waldemar Ferreira e Nereu Ramos, que foram muito applaudidos.

Fez-se logo o maior silencio.

E' quie se havia levantado para falar o professor Henrique Ferri.

Começa dizendo agradecer a prova de estima que the davam naquelle momento-os lentes, seus collegas, pela voz do eminente Director, e pela do preclaro professor Candido Motta, cujas idéas elogiou calorosamente, e os alumnos pela voz de seus interpretes. E agradecia tanto mais penhorado porque via que a manifestação éra espontanea e sincera. 
Faz um estudo comparativo da escola classica e da escola positiva; accentuando que a segunda havia trazido para a sciencia um maior conjunto de verdades. Entretanto o advento da escola positiva é apenas um passo a mais no caminho da sciencia e se o seu nome está ligado a esse movimento isso é um facto puramente accidental. A sua contribuição é o resultado da sua organisação physico-psychica, devida aos antecedentes maternos. Cumpre a mocidade continuar a obra encetada pela sua geração e, sobretudo, a mocidade dos paizes novos melhor póde executar essa missão porque não tem a impedir-lhe os passos a força da tradição e da rotina. Vê que as modernas idéas scientificas encontram aqui um terreno propicio e incita á mocidade a continuar nessa orientação, buscando na sciencia e no trabalho, que são as duas forças verdadeiramente criadoras, a fonte da felicidade e do progresso da humanidade.

O discurso do eminente professor, pronunciado corn grande calor, e em fórma realmente elevada, provocou os mais enthusiasticos applausos não só dos estudantes como da Congregação.

Em seguida o Director em ligeiras palavras congratulou-se com a Faculdade pela recepção dessa visita, e levantou a sessão, retirando-se o professor Ferri com as mesmas honras e acclamações até á porta do edificio, onde se despedio dos lentes e do corpo academico. 